\title{
Practical Advances in Sport Coaching Research in International Sport Coaching Journal
}

Volume 8, Issue 3 will be the last to publish manuscripts under the headings of Best Practices, Insights, and Coaching In. Starting in 2022 (Volume 9), manuscripts that focus on best practices of efforts, ideas, or evidence-based guidelines that can be used to improve coaching, those that focus on well-reasoned and effectively articulated insights and commentaries intended to stimulate thought about coaching, and perspectives of coaching and coach education in different countries and cultures will be categorized under the umbrella term of Practical Advances (International Sport Coaching Journal [ISCJ], 2021a). This new heading will allow for greater flexibility of submissions that are partially data driven to practitioner informed, while not losing the practical nature of these submissions. We will continue to have $70-80 \%$ of each issue devoted to Original Research studies, and 20-30\% of each issue dedicated to Practical Advances. All papers, with the rare exception of invited papers, will undergo double-blind peer review.

While adopting a strongly applied orientation, papers published under the heading of Practical Advances will still be written in an academic style that includes citations, as well as other applied evidence, to support and develop ideas. Thus, Practical Advances will encompass International Sport Coaching Journal (ISCJ) legacy article types of Best Practices, Insights, and Coaching In (ISCJ, 2021a).

This evolution comes alongside a revision to ISCJ's mission. The revision brings into focus ISCJ's interest in expanding understanding of the coaching process, coaching environment, coach education and development, coaching practices, and coaching profession. Therefore, the mission is to advance the research and development of sport coaching worldwide. This mission is pursued through a specific focus on the practice and process of coaching, with consideration also given to the many factors that influence coaching. Thus, ISCJ publishes peer-reviewed, scientific research studies and articles on practical advances about, with, and for coaches (ISCJ, 2021c).

In Volume 8, Issue 3, along with a series of original research articles, coaching in, best practices, and insights, we are publishing an invited article that is intended to showcase ISCJ as a nonproprietary venture of the International Council for Coaching Excellence (ICCE). This article outlines a transparent process of the ICCE's Research Committee in developing, implementing, and reporting the findings of a consultation process and proposal for governance and service agenda. In this invited article, the Research Committee broadly connects the current state of the field of sport coaching research to the ICCE specifically. This project began during discussions at the Research Fair for the ICCE's Global Coach Conference in Japan 2019 (North et al., 2021).

Sport coaching is a relatively young field of research and growing in popularity. The analogy is that it is now a "teenager," as far as fields of research go. Using that analogy, we can think about its current state and project into the future as it moves through this adolescent phase. We often advocate for children's multisport sampling. Into athletes' adolescence, coaches begin to support, promote, and provide direction to these athletes in various developmental trajectories so that these individuals can figure out how to build off one another's strengths and expertise (creating a stronger team), while also innovating in specialized positions. Likewise, sport coaching research as a field has grown through a sampling of disciplinary and methodological frameworks, pushing boundaries (like only a teenager does), trying to figure out answers to various questions.

Our adolescent field has the fundamental skills (aka disciplinary grounding) in psychology, sociology, management, education, and sport sciences, but has progressively developed as a discipline of its own. We need original research studies and practical advances from both academics and practitioners (and "pracademics") in sport coaching. This is a sport coaching journal. It is not a sport psychology journal that publishes coaching studies, nor a sport sociology journal that publishes coaching studies, nor a sport sciences journal that publishes coaching studies. Studies and practical advances published in ISCJ are sport coaching research.

We have editorial board members with expertise across a range of coaching topics from coach education and development, coaching relationships and identities, talent development, equity, diversity, and inclusion, to pedagogy/andragogy, sociology, psychology, philosophy, and qualitative and quantitative methods. Our number of submissions is increasing. We have launched a call for papers for our second special issue (exploring coaching delivery in an online/digital environment; ISCJ, 2021b), and will have our first supplementary issue that publishes the abstracts from the ICCE's Global Coach Conference in November 2021.

The Web of Science Group regularly updates the impact factors in its Journal Citation Reports. Web of Science Group houses the Emerging Sources Citation Index base, which comprises journals with high growth potential. ISCJ is listed in the Emerging Sources Citation Index, which is an excellent step considering the age and size of the journal. As ISCJ gains impact (as measured by number of citations per citable articles), it will reach the point of being listed in one of the Web of Science's citation indexes that provide an impact factor. In the meantime, Comunicar (2021) publishes and updates the list of journals in the Emerging Sources Citation Index, classifying them, according to their citations, in deciles, percentiles with their impact factor simulator. While this ranking is a simulation and is not a formal indication of rank, and while Comunicar does not have any connection to Human Kinetics or Clarivate Analytics, for 2020 they have ranked ISCJ 15 th of 487 journals indexed in education, with a simulated impact factor of 2.000. This simulated impact factor is strong across the sport and education research fields.

In concluding with the analogy of the developmental age of sport coaching research as a field, we have strong foundations from sport coaching research's beginnings until now. We have the vigor of adolescence, along with its inquisitive thirst for more knowledge 
(and its critical fighting spirit, which can help us dig deeper). We can work within and across pockets of expertise to build this field of research. The team at $I S C J$ looks forward to receiving submissions for sport coaching original research studies and practical advances to further the discussion, innovation, and concepts within the burgeoning field of sport coaching research..

Bettina Callary, Editor-in-Chief

\section{References}

Comunicar. (2021). Global ranking-Emerging Source Citation Index (ESCI) (WoS)-2021. Retrieved from https://www.revistacomunicar. com/index.php?contenido=ranking-revistas-esci\&idioma=en
International Sport Coaching Journal. (2021a). Authorship guidelines. Retrieved from https://journals.humankinetics.com/view/journals/ iscj/iscj-overview.xml?tab_body=null-7643

International Sport Coaching Journal. (2021b). ISCJ Special Issue Call for Papers: Exploring coaching delivery in an online/digital environment. Retrieved from https://journals.humankinetics.com/page/iscjspecial-issue

International Sport Coaching Journal. (2021c). Mission. Retrieved from https://journals.humankinetics.com/view/journals/iscj/iscj-overview. $\mathrm{xml}$ ?tab_body=null-7641

North, J., Callary, B., Dieffenbach, K., Galatti, L., Lara-Bercial, S., Nash, C., \& O'Connor, D. (2021). A reflection on the state of sport coaching research, its community, and representation: The 2020 ICCE Research Committee consultation, and early proposals for governance and a service agenda. International Sport Coaching Journal, 8(3). doi:10.1123/iscj.2021-0041 